\title{
Psychological Distress and Physiological Markers: Differences Comparison in First Division Football Players
}

\author{
Farah Layth Naji, Tengku Fadilah Tengku Kamalden*, Saidon Amri \\ Department of Sport Studies, Faculty of Educational Studies, Universiti Putra Malaysia, Malaysia \\ *Corresponding Author: tengku@upm.edu.my
}

Received November 4, 2019 ; Revised December 10, 2019 ; Accepted December 25, 2019

Copyright $(2020$ by authors, all rights reserved. Authors agree that this article remains permanently open access under the terms of the Creative Commons Attribution License 4.0 International License

\begin{abstract}
This study aimed to determine the level of stress as measured through different stress measurement methods (DASS questionnaire, SIgA, pulse rate and oxygen saturation). The highest scores for depression, anxiety, stress, pulse rate were before the competition $(\mathrm{M}=8.365, \mathrm{SD}=2.733),(\mathrm{M}=8.689, \mathrm{SD}=3.962),(\mathrm{M}=10.068$, $\mathrm{SD}=3.094),(\mathrm{M}=63.27, \mathrm{SD}=5.008)$ respectively. While for salivary IgA and oxygen saturation, the highest score was at resting time $(\mathrm{M}=112.147, \quad \mathrm{SD}=14.431), \quad(\mathrm{M}=98.3$, $\mathrm{SD}=1.893$ ) respectively. Descriptive method was used for data collection. Participants were 74 football players of all the first division clubs in Karbala, Iraq, aged between 18-22 years old. Depression, anxiety and stress were measured at three different time points (resting time, before the training, before the competition), while salivary $\mathrm{IgA}$, pulse rate, and oxygen saturation measurement were measured through five different time points (resting time, before the training, after the training, before the competition, after the competition). It can be concluded that the combination of psychological distress and physiological markers can provide accurate measurements of stress.
\end{abstract}

Keywords Psychological Distress, Physiological Markers, Depression, Anxiety \& Stress

\section{Introduction}

A wide range of factors such as physical fitness, stress, nutrition, game load, injuries and finance have an impact on the performance of footballers (Ivarsson, Johnson \& Podlog, 2013). This situation put the players under high pressure before and during the game (Dahl, 2013). Luckily, sports psychologists can control this situation by examining psychological and psychophysiological stress levels of the individual through different measurement methods for the analysis of heart rate, oxygen saturation, salivary IgA, DASS questionnaire (Noyan \& Cohen, 2013; Hegberg \& Tone, 2015; Pennebaker, 2012). The majority of the football players especially in Iraq suffer from pre-match stress. This situation happens because of hectic playing schedules, high-level competition, expectations of fans and continuous media reports. This is why measurement method of physiological markers such as hormones (cortisol), antibodies (IgA), heart-rate, blood pressure and oxygen saturation should be used concurrently upon football players so that their mental health is always on checked. However, some of these methods are expensive and it is difficult to carry out especially at Iraq. That is why this article has come out with objective of determining the level of stress among the football players of the first division clubs in Karbala using different stress measurement methods (DASS questionnaire, SIgA, Pulse rate and Oxygen Saturation) at different stages (during resting time, before training match, after training match, before competition match and after competition match). It is believed that the findings of this article are useful as it can contribute to improving the knowledge of the coaches and football players to deal with stress, by giving an idea if physiological markers can be used to measure stress and can be used in a combination with the DASS questionnaire to provide more accurate results.

\section{Psychological Distress and Physiological Markers}

Psychological distress is defined as a state of emotional suffering characterized by depression symptoms (e.g., loss of interest; sadness; hopelessness) and anxiety (e.g., restlessness; feeling tense) (Mirowsky \& Ross, 2002). These side effects might also be related to somatic symptoms (e.g., insomnia; headache; lack of energy) that 
probably vary across cultures (Kirmayer, 1989; Kleinman, 2008). Some sources indicated that stress originates from a Latin word called 'stringere', which means 'binding tightly'. Others indicate that it originates from a French word 'destresse', which means 'anglicized to distress'. Later, the word 'dis' was eliminated and finally left with the word stress only (Stevens et al., 2013). Fletcher and Scott (2010) found that psychological distress has a negative impact on athletes' stress which causes anxiety and depression in their nature, this situation in the end will affect the immune system of athletes'. A study of Filaire, Lac, and Pequignot (2003) showed that the performance of the players with the presence of stress before the competitions and during the training decreases with changes in their physiological states. It is also suggested that a combination of both psychological and physiological changes during the training and competition is of essential interest to measure the training and competition stress associated with performance in the team activity. This where are the unique format to identify stress which is Depression Anxiety Stress Scales (DASS) questionnaire can be used to determine the level of stress among the football players because of its unique format. DASS is a commonly used screening tool to assess signs of depression, anxiety, and stress in the community. This instrument includes three subscales which are the depression scale, the anxiety scale and stress scale. Another way of identifying stress among football players that can be used along with DASS is physiological tests. This test includes three approaches which are the Salivary IgA test (performed to measure the level of an immunoglobulin of athletes' body), pulse rate (detecting the exercise tolerance testing against stress) and oxygen saturation testing (determining the abnormal state of heart). The combination of DASS and physiological tests is important because the DASS instrument is unable to assess the various side effects of depression and it is not intended to supplant a thorough clinical meeting (Bourgeois et al., 2010; Masten, 2006). Therefore as suggested by some studies, physiological markers such as salivary IgA, pulse rate, and oxygen saturation can be used in a combination with psychological distress to confirm the results and determine the effect of psychological stress (Hegberg \& Tone, 2015; Pennebaker, 2012).

\section{Methodology}

The sample was randomly selected based on the existing football clubs in Karbala province. Therefore, all of the first division clubs who participant in a new season (2016-2017) were selected; namely Al-husseiniya club, Al-hur club, Al-gadharah club, Al-hindiea club and all clubs. The total number of football players in four clubs was $(n=114)$. However, 40 players were excluded (11 players were injured; 13 players were unhealthy because of smoking, addicting to drug, and drinking alcohol; 4 players received antibiotic therapy for two months before the study; 2 players took anti-inflammatory drug, 7 players took supplementation, and 3 players caught a cold). Therefore, the total number of player participants in this study was $(n=74)$. They were in the 18-22 age range, and all of them have 3 or more years of football playing experiences. All of the player participants are male. Below is the number of players in each club:

Table 1. The Number of Players in each Club

\begin{tabular}{clccc}
\hline No. & \multicolumn{1}{c}{ Clubs } & $\begin{array}{c}\text { Number of the } \\
\text { players }\end{array}$ & Excluded & Included \\
\hline l. & Al-Husseiniya Club (A) & 28 & 10 & 18 \\
2. & Al-Hur Club (B) & 30 & 10 & 20 \\
3. & Al-Gadharah Club (C) & 27 & 9 & 18 \\
4. & Al-Hindiea Club (D) & 29 & 11 & 18 \\
Total & & 114 & 40 & 74 \\
\hline
\end{tabular}

All respondents were screened to ensure that there were no contraindications to respondent. These respondents were provided with information on their level of comprehension of the purposes, methods, demands, risks, inconveniences, discomforts and possible outcomes of this research. The experimental procedure was approved by the Human Research Ethics Committee of Universiti Putra Malaysia, Karbala football clubs and coaches of the teams. Four variables including DASS questionnaire, salivary IgA, pulse rate and oxygen saturation were measured among football players as represented below:

Table 2. Instruments

\begin{tabular}{cccc}
\hline No. & Instruments & Type & Details \\
\hline 1. & DASS & questionnaire & 21 questions \\
2. & Salivary IgA & marker & Collecting saliva $(2 \mathrm{ml})$ \\
3. & Pulse rate & marker & Measure pulse rate $(\mathrm{bpm})$ \\
4. & Oxygen saturation & marker & Measure oxygen saturation $(\%)$ \\
\hline
\end{tabular}

Pre-test for this study was done by a panel of experts. They were consulted to evaluate the validity of the questionnaire by reviewing and judging the instruments of the study to define the content and face validity of DASS instrument as well as the instrument for measuring the salivary IgA, plus rate and also oxygen saturation. The pilot of the instrument was conducted with 25 respondents to measure the reliability of the DASS instrument. The data collection was done after the schedule of each club that contains date and time of resting and competition received by the researcher, then the researcher made plan for each club to collect the data depending on the club's schedule. Collected data were coded and analyzed using Statistical Package for Social Science (Version 21.0). Descriptive statistics (frequency, percentage, mean, and standard deviation), as well as inferential statistics (one-way repeated measures ANOVA) were applied to answer the research question. 


\section{Result}

The demographic information gives the details of age and years of experience for the players are shown below:

Table 3. Demographic Details of Players in each Club

\begin{tabular}{clccc}
\hline No. & \multicolumn{1}{c}{ Clubs } & $\begin{array}{c}\text { Number of the } \\
\text { players }\end{array}$ & $\begin{array}{c}\text { Age } \\
\text { Mean } \pm \text { SD }\end{array}$ & $\begin{array}{c}\text { Years of experience } \\
\text { Mean } \pm \text { SD }\end{array}$ \\
\hline 1. & Al-Husseiniya Club (A) & 18 & $18.89 \pm 0.76$ & $4.21 \pm 0.70$ \\
2. & Al-Hur Club (B) & 20 & $20.8 \pm 1.20$ & $4.44 \pm 0.84$ \\
3. & Al-Gadharah Club (C) & 18 & $19.83 \pm 1.62$ & $4.02 \pm 0.73$ \\
4. & Al-Hindiea Club (D) & 18 & $19.83 \pm 1.50$ & $4.24 \pm 0.74$ \\
Total & & 74 & $19.86 \pm 1.46$ & $4.23 \pm 0.76$ \\
\hline
\end{tabular}

The result of DASS sub-scale for depression indicated that the variable among respondents during rest time was $6.027 \pm 1.158$ (Mean $\pm \mathrm{SD}$ ) before the training was $7.419 \pm 2.601$ and it increased before the competition to $8.365 \pm 2.733$. The results of the Bonferroni test showed that there were significant differences in depression between resting time and before the training $(\mathrm{p}=0.001)$, resting time and before the competition $(\mathrm{p}=0.001)$. However, there was no significant difference between before training and before the competition $(\mathrm{p}=0.066)$.

Table 4. Comparison of Depression among Different Measurements

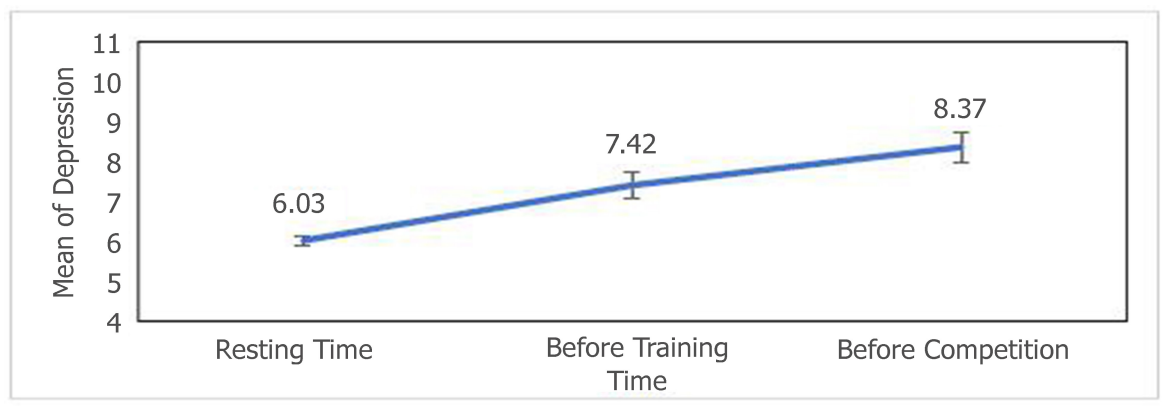

The result of DASS sub-scale for anxiety indicated that the variable among respondents during rest time was $5.568 \pm 2.353$ (Mean $\pm \mathrm{SD}$ ) before the training was $6.541 \pm 2.602$, and it increased before the competition to $8.689 \pm 3.962$. The results of the Bonferroni test showed that there were significant differences between resting time and before training $(\mathrm{p}=0.044)$, resting time and before the competition $(\mathrm{p}=0.0001)$, before training and before the competition $(\mathrm{p}=0.0001)$.

Table 5. Comparison of Anxiety among Different Measurements

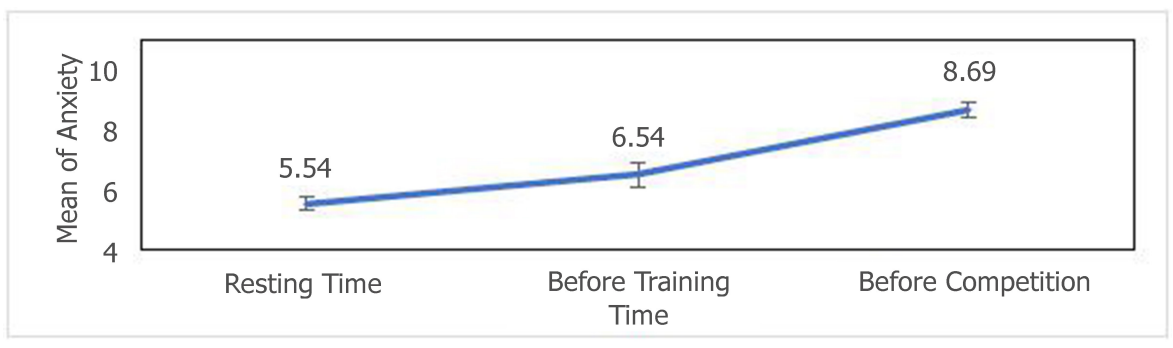

The result of DASS sub-scale for stress indicated that during rest time was $7.297 \pm 0.989(\mathrm{Mean} \pm \mathrm{SD})$ before the training $8.230 \pm 2.723$, and it increased before the competition to $10.068 \pm 3.094$. The results of the Bonferroni test showed significant differences in the total scores on stress between resting time and before the training $(\mathrm{p}=0.014)$, resting time and before the competition $(\mathrm{p}=0.001)$, before training and before the competition $(\mathrm{p}=0.001)$. 
Table 6. Comparison of Stress among Different Measurements

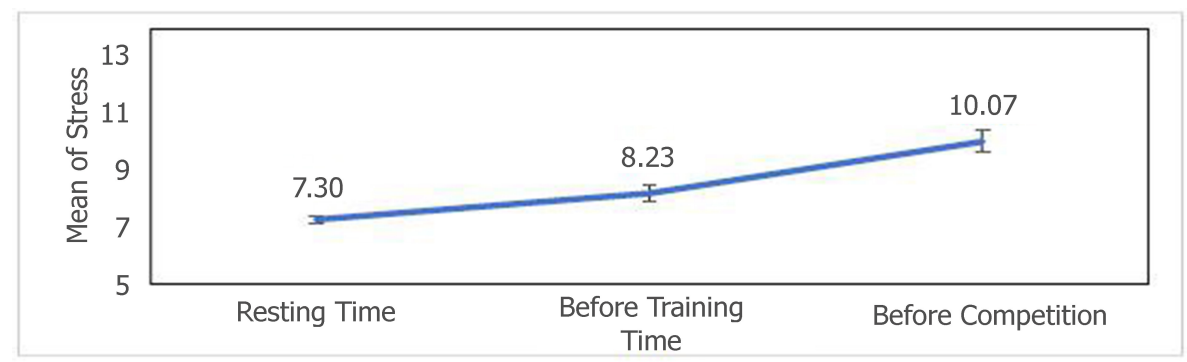

The result of physiological tests for Salivary IgA indicated that during rest time was $112.147 \mathrm{ug} / \mathrm{mL} \pm 14.431$ (Mean $\pm \mathrm{SD}$ ), before the training $104.412 \mathrm{ug} / \mathrm{mL} \pm 15.013$. Then it decreased after the training to $86.539 \mathrm{ug} / \mathrm{mL} \pm 13.878$, and the lowest level was found before the competition was $55.160 \mathrm{ug} / \mathrm{mL} \pm 14.521$, after the competition again, salivary IgA increased to $68.106 \mathrm{ug} / \mathrm{mL} \pm 14.399$. The results of the Bonferroni test showed significant differences between resting time and after the training, resting time and before competition, resting time and after the competition, before the training and after the training, before the training and before the competition, before the training and after the competition, before the competition and after the competition $(\mathrm{p}=0.001)$ for all, after the training and after the competition $(\mathrm{p}=0.012)$. However, resting time and before the training $(\mathrm{p}=0.644)$, after the training and before the competition $(\mathrm{p}=0.081)$ were not significant.

Table 7. Comparison of Salivary IgA among Different Measurements

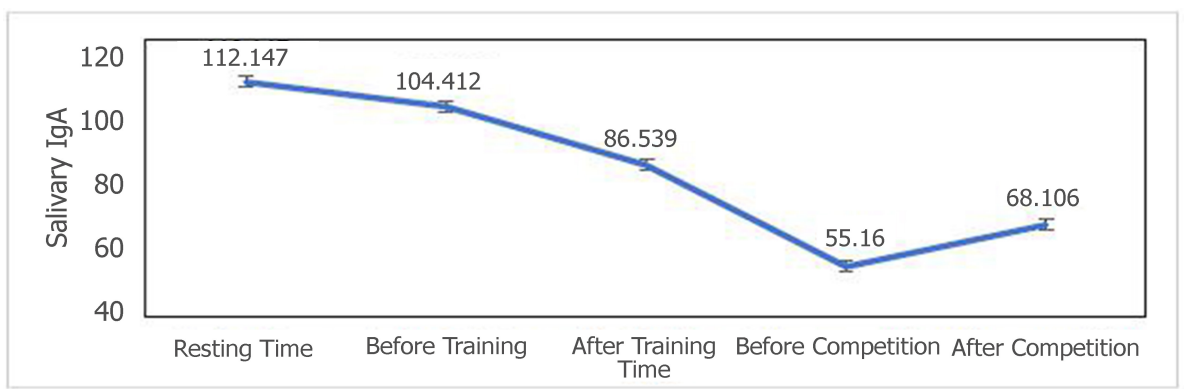

The result of physiological tests for pulse rate indicated that during rest time was $54.65 \mathrm{bpm} \pm 4.042$ (Mean $\pm \mathrm{SD}$ ), before the training was $57.43 \mathrm{bpm} \pm 3.85$, and it decreased after the training to $60.49 \mathrm{bpm} \pm 6.71$, and before the competition, its rate increased to $63.27 \mathrm{bpm} \pm 5.008$, but after the competition match, it decreased to $62.78 \mathrm{bpm} \pm 7.888$. The results of the Bonferroni test showed that there were no significant differences in pulse rate among these measurements between after the training and before the competition $(\mathrm{p}=0,071)$, after the training and after competition $(\mathrm{p}=0.726)$, before the competition and after the competition $(\mathrm{p}=1)$. While between resting time and before the training, resting time and after the training, resting time and before the competition, resting time and after competition, before the training and after the training, before the training and before the competition, before the training and after the competition showed a significant difference $(\mathrm{p}=0.001)$.

Table 8. Comparison of Pulse Rate among Different Measurements

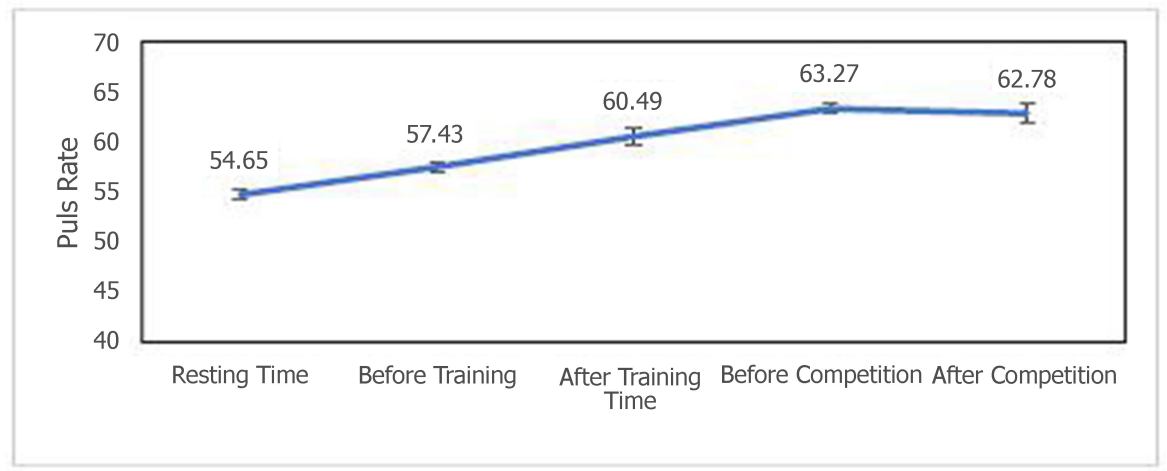


The result of physiological tests for oxygen saturation indicated that during rest time was $98.3 \% \pm 1.893$ (Mean \pm SD), before the training was $97.99 \% \pm 3.624$. Oxygen saturation after training was $97.05 \% \pm 2.426$. Meanwhile, before the competition, it decreased to $95.38 \% \pm 3.568$, but after the competition, it increased to $96.49 \% \pm 1.874$. The results of the Bonferroni test showed no significant differences in mean scores on oxygen saturation between resting time and before the training $(\mathrm{p}=1)$, before the training and after the training $(\mathrm{p}=0.283)$, after the training and after the competition $(\mathrm{p}=1)$, before the competition and after the competition $(\mathrm{p}=0.075)$. But it showed a significant difference between resting time and after the training $(\mathrm{p}=0.013)$, resting time and before the competition $(\mathrm{p}=0.001)$, resting time and after the competition $(\mathrm{p}=0.001)$, before the training and before the competition $(\mathrm{p}=0.001)$, before the training and after the competition ( $\mathrm{p}=0.02)$, after the training and before the competition $(\mathrm{p}=0.019)$.

Table 9. Comparison of Oxygen Saturation among Different Measurements

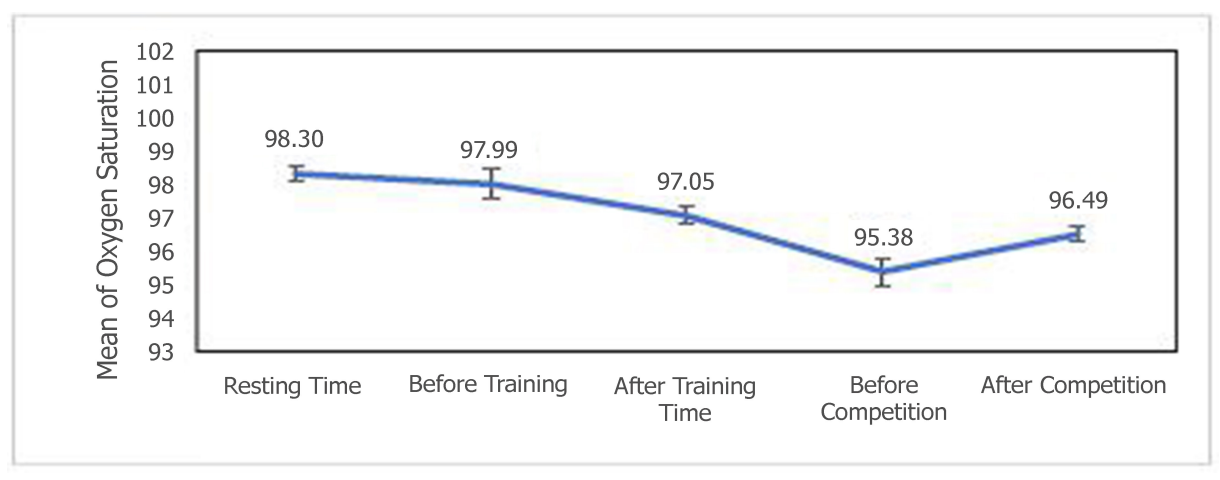

\section{Discussion}

The results in terms of depression showed that they were not significant. These findings show a significant change in depression level at the three times such as resting time, before the training and before the competition among football players. The highest score was found before the competition. This result is similar to previous research that suggests a high score on depression of players before the match. The main reason could be related to the age of the subjects in the current study (Dukic, 2011).

In terms of anxiety, the results showed that there were significant differences between resting time and before training, resting time and before the competition, before the training and before the competition. The highest score was found before the competition period. This result is similar to previous research which showed a significant difference in the training time among the players, it could be explained by characteristics of the players such as playing level (Junge \& Feddermann-Demont, 2016).

The results of the measure stress showed that there were significant differences between resting time and before the training, resting time and before the competition, before the training, and before the competition. The highest score was found before the competition. This result is similar to previous research that argues high level of stress among subjects happen before the competition, this similarity might be related to same subject age (Dukic, 2011). These findings are supported by the theory mentioned by Hart et al. (2013), the stress that occurs in the competition can influence the performance of the competitors and influence their hormones leading to a negative influence on their performance.

The salivary $\operatorname{IgA}$ results showed that there were significant differences between resting time and after the training, resting time and before the competition, resting time and after the competition, before the training and after the training, before the training, and before the competition, before the training and after the competition, before the competition and after the competition, after the training and after the competition. However, there were no significant differences between resting time and before the training, after the training and before the competition. These findings could be due to the training load which can affect the level of IgA. In competition, with a decrease in the level of stress, the level of IgA again increased. Increasing the level of stress could be due to the competition which decreases the level of IgA and negatively affects immunological parameters of athletes. It should be noted that the secretion of salivary hormones, especially IgA could be affected by environmental parameters such as anxiety, stress, and depression.

The pulse rate results of the current study showed that there were significant differences between resting time and before the training, resting time and after the training, resting time and before the competition, resting time and after the competition, before the training and after training, before the training and before the competition, before the training and after the competition. However, there were no significant differences between after training and before the competition, after training and after competition, before the competition and after competition. The highest 
pulse rate was found before the competition, but it significantly decreased after the competition. This result might be related to the effect of stress and anxiety on hormones and catecholamine, and for a long time, it can be harmful to the athletes. In addition, it might link to the same subjects of the study who is professional soccer players. It should be noted that Bangsbo et al., (2015) measured the heart rate at different time points, and mentioned that this rate is acceptable among elite athletes rather than recreation athletes. There is less stress and anxiety in response to the competition compared with elite athletes.

In terms of oxygen saturation the results showed that there were significant differences between resting time and after the training, resting time and before the competition, resting time and after the competition, then before the training and before the competition, before training and after the competition, after the training and before the competition. However, there were no significant differences between resting time and before the training, before the training and after the training, after the training and after the competition, before the competition and after the competition. The lowest oxygen saturation was found before the competition, and it increased after the competition, but was not statistically significant. The results of this study showed that oxygen saturation decreased after the training. These results could be related to the high level of performance and again decreased before the competition which might be related to the negative effect of stress, anxiety, and depression caused by the competition on their physiological and physical performance. This might be related to the effect of competition on oxygen saturation of football players and its relationship with physiological parameters.

\section{Recommendations and Conclusion}

So far, a number of studies have measured the level of depression, anxiety, stress, salivary IgA, pulse rate and oxygen saturation among the football players in Iraq. Having some easy and standard methods to measure these parameters at different times (during resting time, before the training, after the training, before the competition, and after the competition) seems important for athletes as these parameters are related to their immunological system and can affect their professional performance. The presented results provide a platform for future experiments, aiming at better understanding the physiological changes associated with football matches. There are some recommendations that are made for this article which are i) further research should be conducted among other types of athletes; ii) further research should determine the difference among different genders in different groups of age; iii) including other immunological parameters variables such as $\operatorname{IgG}$ and $\operatorname{IgM}$ and; iv) finding a relationship among depression, anxiety, stress, SIgA, pulse rate, and oxygen saturation to determine which variables are correlated. Although the results of this research are practical and have useful implications, some limitations should be considered when interpreting the results such as the circumstances of the surrounding areas (weather temperature, pollution and samples/ football player body health). Some of delimitations also needed to be taken into taken into account such as the only participation of first division clubs of Karbala province in the first division league season (2016-2017 between 18 and 22 of age male) as the sample and Karbala is the safest province to do the research (since Iraq is one of the war regions).

\section{REFERENCES}

[1] Bangsbo, J., Hansen, P. R., Dvorak, J., \& Krustrup, P. (2015). Recreational football for disease prevention and treatment in untrained men: a narrative review examining cardiovascular health, lipid profile, body composition, muscle strength and functional capacity. Br J Sports Med, 49(9), 568-576.

[2] Bourgeois, A., LeUnes, A., \& Meyers, M. (2010). Full-scale and short-form of the Profile of Mood States: A factor analytic comparison. Journal of Sport Behavior, 33(4), 355.

[3] Dahl, K. D. (2013, September 4). External Factors and Athletic Performance. Retrieved from http://digitalcommons.liberty.edu/honors/347.

[4] Dukic, J. (2011). Dualistic model of passion and mental health in a sample of Canadian student-athletes (Doctoral dissertation).

[5] Filaire, E., Lac, G., \& Pequignot, J.-M. (2003). Biological, hormonal, and psychological parameters in professional soccer players throughout a competitive season. Perceptual and Motor Skills, 97(3_suppl), 1061-1072.

[6] Fletcher, D., \& Scott, M. (2010). Psychological stress in sports coaches: A review of concepts, research, and practice. Journal of Sports Sciences, 28(2), 127-137.

[7] Hart, J., Kraut, M. A., Womack, K. B., Strain, J., Didehbani, N., Bartz, E., \& Cullum, C. M. (2013). Neuroimaging of cognitive dysfunction and depression in aging retired National Football League players: a cross-sectional study. JAMA neurology, 70(3), 326-335.

[8] Hegberg, N. J., \& Tone, E. B. (2015). Physical activity and stress resilience: Considering those at-risk for developing mental health problems. Mental Health and Physical Activity, 8, 1-7.

[9] Hegberg, N. J., \& Tone, E. B. (2015). Physical activity and stress resilience: Considering those at-risk for developing mental health problems. Mental Health and Physical Activity, 8, 1-7.

[10] Ivarsson, A., Johnson, U., \& Podlog, L. (2013). 
Psychological predictors of injury occurrence: a prospective investigation of professional Swedish soccer players. Journal of sport rehabilitation, 22(1), 19-26.

[11] Junge, A., \& Feddermann-Demont, N. (2016). Prevalence of depression and anxiety in top-level male and female football players. BMJ open sport \& exercise medicine, 2(1), e000087.

[12] Kirmayer, L. J. (1989). Cultural variations in the response to psychiatric disorders and emotional distress. Social Science \& Medicine, 29(3), 327-339.

[13] Kleinman, A. (2008). Rethinking psychiatry. New York, United States of America: Simon and Schuster.

[14] Masten, R., Tušak, M., \& Faganel, M. (2006). Impact of identity on anxiety in athletes. Kinesiology, 38(2), 126-134.

[15] Mirowsky, J., \& Ross, C. E. (2002). Measurement for a human science. Journal of Health and Social Behavior, 152-170.

[16] Noyan, I. C., \& Cohen, J. B. (2013). Residual stress: measurement by diffraction and interpretation. Retrieved from http://books.google.com.

[17] Pennebaker, J. W. (2012). The psychology of physical symptoms. Retrieved from http://books.google.com.

[18] Stevens, R. E., Loudon, D. L., Yow, D. A., Bowden, W. W., \& Humphrey, J. H. (2013). Stress in college athletics: Causes, consequences, coping: Routledge. 